Article

\title{
Simulating the Impacts of Hybrid Campus and Autonomous Electric Vehicles as GHG Mitigation Strategies: A Case Study for a Mid-Size Canadian Post-Secondary School
}

\author{
Bijoy Saha * and Mahmudur Rahman Fatmi (D)
}

\section{check for}

updates

Citation: Saha, B.; Fatmi, M.R. Simulating the Impacts of Hybrid Campus and Autonomous Electric Vehicles as GHG Mitigation Strategies: A Case Study for a Mid-Size Canadian Post-Secondary School. Sustainability 2021, 13, 12501. https://doi.org/10.3390/su132212501

Academic Editors: Feng Zhu,

Wenbo Zhang, Yuntao Guo and Jian Wang

Received: 21 October 2021 Accepted: 10 November 2021 Published: 12 November 2021

Publisher's Note: MDPI stays neutral with regard to jurisdictional claims in published maps and institutional affiliations.

Copyright: (c) 2021 by the authors. Licensee MDPI, Basel, Switzerland. This article is an open access article distributed under the terms and conditions of the Creative Commons Attribution (CC BY) license (https:// creativecommons.org/licenses/by/ $4.0 /)$.
School of Engineering, Civil Engineering, Okanagan Campus, The University of British Columbia, Kelowna, BC V1V 1V7, Canada; mahmudur.fatmi@ubc.ca

* Correspondence: bijoy.saha@ubc.ca; Tel.: +1-250-317-5835

\begin{abstract}
This paper presents how a post-secondary institution like University of British Columbia's Okanagan (UBCO) campus can reduce its carbon footprint and be aligned with the government's target through promoting virtual campus and autonomous electric vehicles (AEVs). Different virtual campus scenarios are developed: online classes only, working-from-home only, and a hybrid of both. In the case of AEVs, alternative penetration rates for levels 2 and 5 are considered. A total of 50 scenarios are tested using a sub-area transport simulation model for UBCO, which is extracted from the regional travel demand forecasting model. The results suggest that a $40 \%$ AEV penetration rate coupled with fully in-person classes reduces GHG by $\sim 36 \%$ compared to the 2018-level, which will help UBCO to achieve their 2030 emission reduction target and be aligned with the provincial target. The $50 \%$ AEV and $10 \%$ hybrid virtual campus reduces emissions by $\sim 48 \%$, which is aligned with the 2040 provincial target. A fully virtual campus will help to reach the 2050 provincial target by reducing GHG by $\sim 76 \%$. The results further demonstrate that level $5 \mathrm{AEVs}$ produce lesser emissions than level 2 at a lower AEV penetration rate for the fully in-person campus scenario. At higher penetration rates, level 5 performs better only if it is coupled with $10 \%$ of students, faculties and staffs attending virtual campus scenario.
\end{abstract}

Keywords: travel demand management; virtual campus; autonomous electric vehicle; macroscopic traffic simulation; scenario planning; climate action plan

\section{Introduction}

The transportation sector is a major contributor of greenhouse gas (GHG) emissions; for example, transportation contributed $29 \%$ of the total GHG emissions in the USA in 2019-higher than any other sector [1]. In Canada, around 25\% of the total GHG comes from transportation [2]. To combat climate change, governments around the world are adopting progressive policies and setting aggressive targets. For example, Canadian NetZero Emissions Accountability Act sets the target of achieving a net-zero emission economy by 2050 [3]. Aligned with the federal target, provinces such as British Columbia (BC) targets to reach $100 \%$ new car sales to be zero-emission vehicles by 2040 and reduce GHG emission by $40 \%$ in 2030 compared to the 2007 baseline [4]. In addition to government agencies, major employers and institutions play a crucial role in achieving these climate emergent targets, as a large portion of the transportation emissions comes from the car-dominant commute travel to work [5]. In this context, post-secondary institutions such as universities could emerge as champions through climate change plans and policies. For example, the University of British Columbia's Okanagan (UBCO) campus has proposed its Climate Action Plan 2030, where the university is working towards attaining a 50-60\% reduction in GHG emission from the transportation sector by 2030 compared to the 2007 level [6]. UBCO is currently in the process of developing its transportation master plan and evaluating 
aggressive GHG mitigation strategies such as flexible work and learning arrangements and parking pricing to reduce their carbon footprint [7].

COVID-19 imposed travel restrictions, and the closure of businesses and educational institutions for the past one year have demonstrated that individuals can successfully perform a wide array of activities, including work and schooling from home. For example, UBC transitioned to fully remote work and online teaching on 16 March 2020, due to the COVID-19 pandemic. The university was fully operational during this period, including teaching, research, and administrative works. Although fully remote working and learning might be challenging in many ways, such as limited social interactions with colleagues and friends and stable internet connections, recent surveys have indicated that many have shown preference towards some form of flexible working and learning arrangements [8]. Such remote learning and working arrangements have tremendous environmental benefits. For example, this helped to reduce daily trips, thus, making a downward trend of travelrelated emissions. Pata [9] analyzed $\mathrm{PM}_{2.5}$ emissions in eight cities in the USA adopting the Fourier causality test. The results showed that there had been a significant reduction of $\mathrm{PM}_{2.5}$ emissions in all those cities during the pandemic. Eregowda et al. [10] assessed the air quality parameters in the metropolitan cities of India during the COVID-19 lockdown and compared them with the pre-COVID period. They revealed that around $48 \%$ population of Hyderabad (i.e., one of the metropolitan cities in India) transitioned to work-from-home, resulting in a $\sim 54 \%$ reduction in vehicular emissions. Han et al. [11] assessed national and provincial-level $\mathrm{CO}_{2}$ emissions from the ground transportation system of China and found a reduction of around $32.7 \%$ from 31 provinces during the first quarter of 2020 compared to the same period of 2019. As we move towards re-opening businesses and institutions, it will be crucial to adopt sustainable travel demand management policies to capitalize on our recent experience, such as telecommuting, to achieve the GHG mitigation targets. For example, Zhang and Zhang [12] examined several scenarios based on expected changes in the post-COVID "new normal" life and found that measures such as working from home, online shopping, and bike-friendly design will reduce $44 \% \mathrm{CO}_{2}$ emissions by 2060.

In addition to travel demand management strategies, adopting emerging technologies such as autonomous and electric vehicles could help to curb emissions to a significant extent. Fernandes et al. [13] developed a macroscopic model in PTV VISUM and tested thirteen scenarios varying the penetration rates of shared vehicles (SVs), electric vehicles (EVs), and automated vehicles (AVs) to calculate $\mathrm{CO}_{2}$ and $\mathrm{NO}_{\mathrm{X}}$ emissions in Centro Region of Portugal. The results suggested that a maximum of $22.5 \% \mathrm{CO}_{2}$ could be reduced with $50 \%$ penetration rates of $\mathrm{SVs}$ and $35 \% \mathrm{NO}_{\mathrm{X}}$ could be reduced by deploying $\mathrm{SVs}$, EVs, and AVs at penetration rate of $33 \%, 18 \%$ and $35 \%$, respectively. Patella et al. [14] utilized travel demand modeling software EMME to investigate how electric AVs could mitigate carbon emission in Rome. They found that $60 \%$ GHG emissions could be deducted for a $100 \%$ AV penetration rate in comparison to the base traffic scenario. Pourrahmani et al. [15] investigated the impact of connected autonomous vehicles (CAVs) on GHG emission reduction in San Francisco, USA, utilizing adopting Integrated Transport and Health Impacts Model (ITHIM). They found that emission of $\mathrm{CO}_{2}$ and $\mathrm{PM}_{2.5}$ can be lowered by $30 \%$ and $5 \%$, respectively, if CAV adopts eco-driving, whereas engine performance improvement can make a $20 \% \mathrm{CO}_{2}$ emission reduction. Hong and Zimmerman [16] estimated vehicle fleet emissions in Metro Vancouver, Canada, utilizing MOtor Vehicle Emission Simulator (MOVES). They developed five scenarios varying transit use, fuel type, and diffusion rates of electric CAVs etc. Their study concluded that a higher emission reduction is possible at a lower diffusion rate (1-5\%) of CAVs. They also suggested that integrated transit-use and shared CAVs can reduce 20\% emission by 2040 compared to a no-CAV scenario. 
To effectively reduce GHG emissions, government policies need to be supported and coupled with similar plans and policies by major employers such as industrial and commercial establishments and educational institutions such as universities. For example, Logan et al. [17] investigated the impact of travel demand management (TDM) initiatives on the students and staffs at the University of Aberdeen and found that measures such as free campus shuttle bus, charged parking permits, cycle infrastructure, etc., can reduce single-occupancy car journeys, and consequently reducing the emissions to a significant extent. Filimonau et al. [18] found that the transition to online teaching and learning reduced $30 \%$ of the carbon footprint in a mid-sized UK university during the pandemic (April-June 2020). However, as most of the universities are planning to get back to inperson class; mainly, in North America, the critical question is: how can schools continue to progress in reducing their carbon footprint and help the government to achieve their target through adopting progressive and emerging GHG mitigation strategies in the post-COVID new normal era?

To answer the above question, this study investigates the impacts of hybrid campus and usage of autonomous electric vehicles (AEVs) on GHG emissions for a mid-sized school campus in Canada-i.e., The University of British Columbia's Okanagan (UBCO) campus. UBCO was established in 2005 and has experienced tremendous growth. For example, the campus population has doubled in the past 10 years-i.e., 5390 in 2008 to 10,600 in $2019[19,20]$. Given the past growth and the plan to expand its capacity to become a community of 20,000 population as outlined in the UBCO Outlook 2040 [21], UBCO's commitment towards managing travel demand and reducing its carbon footprint will be a challenging task. UBCO is working together with the provincial and federal governments to come up with innovative solutions in reducing GHG emissions. In this regard, this study develops a travel demand forecasting model for the UBCO campus and tests different what-if scenarios to identify the effective measures. This model is basically a subarea model extracted and upgraded from the regional travel demand forecasting model. First, this study upgrades the regional model, specifically the mode choice component and validates it. Then, the sub-area model for the UBCO campus is extracted. The traffic assignment component of the sub-area model is further calibrated and validated. Following that, futuristic what-if scenarios are tested for the UBCO campus, which are aligned with the Canadian government's targets as well. For example, the tested use cases are: how could hybrid work arrangement-i.e., different shares of staffs and faculties telecommuting in the post-covid era reduce travel-related emissions? How could hybrid classroomsi.e., different shares of online classes and the rest in-person help to reduce GHG emissions? What if UBCO promotes the use of AEV to reach climate action goals? This cutting-edge technology is becoming a popular tool to curb the emission across the world. Many educational institutions, such as the University of Delaware, USA, have autonomous vehicle test-bed facilities to experiment with this technology [22]. In addition to testing the above scenarios separately, this study also provides insights into different combinations of these scenarios. The findings provide insights on what policies could be adopted to achieve the campus and provincial government's short-, intermediate-, and long-range GHG mitigation targets. The findings of this study will provide direct evidence to UBCO and are expected to assist in developing and tracking the progress of their transportation master plan. 


\section{Study Area}

The study area is the University of British Columbia's Okanagan (UBCO) campus. This young and mid-sized university is located in the Central Okanagan region-south of the Province of British Columbia (BC), Canada. The university is located in the North end of the City of Kelowna and can be accessed through a highway exit. UBCO was established in 2005 with 3500 students. Current campus population is $\sim 12,300$, including $~ 10,800$ students (i.e., included both undergraduate and graduate students) and $~ 1500$ faculty/staff [20]. In 2019 , the daytime population in UBCO was $\sim 10,500$, which is expected to increase in the future significantly. These increased number of trips will contribute to GHG emissions, which need to be addressed. To combat climate changes, the university has documented Climate Action Plan (CAP) 2030 [6]. CAP 2030 outlines separate targets to reduce campus operation emissions and extend impact emissions. Campus operation emissions include emissions from existing buildings and energy supply. On the other hand, emissions from commuting, food system, and waste material have been considered as extended impact emissions. UBCO targets to achieve 50-60\% emission reduction from commuting by 2030, where the baseline is the emissions in 2013. The document reports that UBCO has already achieved $\sim 21 \%$ emission reduction from the transportation sector in 2018. UBCO is also working with the government of $\mathrm{BC}$ to mitigate emissions. The government of $\mathrm{BC}$ has manifested its GHG mitigation strategy in the CleanBC plan [4] and set progressive targets. For example, BC will endeavor to achieve $40 \%, 60 \%$ and $80 \%$ overall emission reduction by 2030, 2040, and 2050, respectively, compared to 2007 baseline emission. It has also reported that a 3.7\% emission reduction had been achieved by 2016. Since transportation is one of the major sources of GHG emissions in BC, it is critical to identify effective solutions for GHG mitigation from this sector. This study investigates how UBCO can achieve its own and the government of BC's short-term (2030), intermediate (2040), and long-term (2050) targets by investigating different scenarios built upon transportation demand management (TDM) and emerging technologies.

To achieve these targets and tracking progress, this study develops a simulation tool to test alternative scenarios and provides insights on reaching the target. To set the spatial scope of the simulation model, it is important to understand the traffic pattern commuting to the UBCO campus. The origins of the UBCO-bound trips during the morning peak period (i.e., $07.00 \mathrm{am}-10.00 \mathrm{am}$ ) are illustrated in Figure 1. Data for this schematic comes from the regional travel demand model. As illustrated, a higher number of trips have originated from the surrounding area of UBCO, where a significant number of on-campus and off-campus student housing is located. Interestingly, a significant number of trips ( $95.6 \%)$ originated outside the UBCO neighborhood. For example, a higher number of trips are also originating from the Rutland ( 14.2\%) and Kelowna Downtown areas ( $\sim 8.6 \%)$. A significant number of trips are coming from other nearby cities; outside of Kelowna, for example, $\sim 7.3 \%$ from West Kelowna and $\sim 7.0 \%$ from Lake Country. Although the focus of this study is on the UBCO campus, it is necessary to include the context of the surrounding area in the model since a major number of trips are coming from outside of the campus. Therefore, a two-step process is adopted in this study. In the first stage, the regional model is upgraded for improved representation of mode choice. In the second stage, a sub-area model for the UBCO campus is extracted from the regional model, which is utilized to simulate the GHG emissions for the campus. 


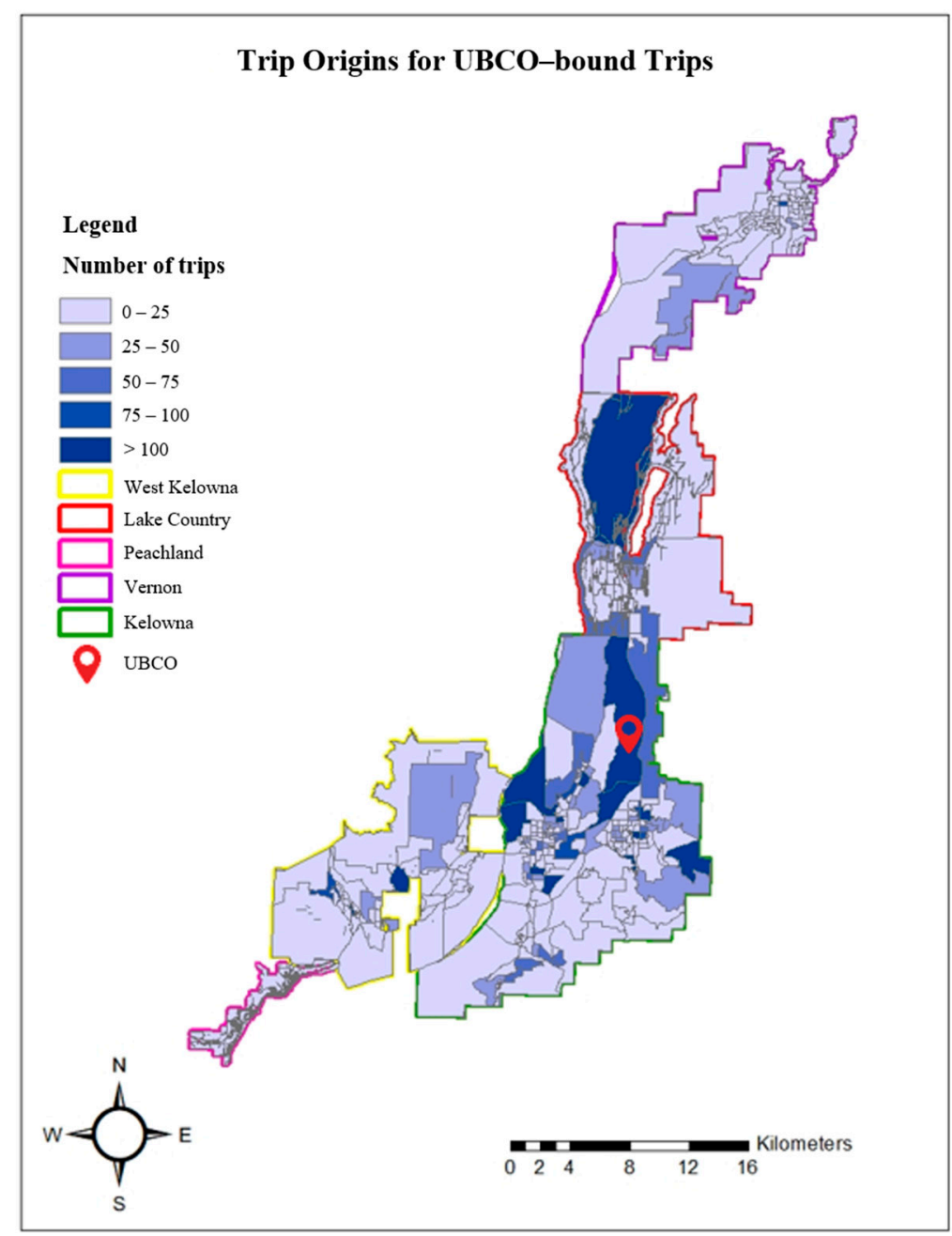

Figure 1. Origins of UBCO-bound trips during the AM-peak period.

\section{Data}

This study utilizes data from several sources. The origin/destination (O/D) matrix is extracted from the regional travel demand model. The regional O/D matrix used in this study is at the dissemination area (DA) level, which is the smallest spatial resolution that Statistic Canada uses to publish their census data. The 2018 Okanagan Travel Survey (OTS) data have been used for developing the mode choice model. This survey has two major components: (1) a 24-h travel diary and (2) socio-demographics. Travel diary collected information regarding trip purpose (i.e., travel to work, post-secondary school, recreation, etc.), trip duration (in minutes), travel mode, O/D location, etc. Travel mode information can be aggregated into the following five groups: (1) car (i.e., auto driver and auto passenger), (2) public transit, (3) walk, (4) bike, (5) others (i.e., taxi, intercity coach bus, school bus, motorcycle, scooter, etc.). Regarding the socio-demographics, the following information were collected: age, gender, income, household size, employment status, and occupation. Additionally, neighborhood characteristics such as population density information are collected from the Statistics Canada's census tabulation. Location of different destinations of interest such as school are collected from the DMTI Spatial Inc. OpenStreetMap has been used to build the road network in PTV VISUM [23] software. General transit feed specification (GTFS) data from BCTransit have been utilized to code transit stops, transit lines, headways, arrival and departure time at each stop into the model. For calibration and validation purposes, traffic count data from the Campus Planning (UBCO), City of Kelowna, and Bluecity sensors have been used. 


\section{Model Development}

Central Okanagan's existing regional travel demand forecasting model follows a four-stage modeling technique. The spatial unit of analysis for the model is the dissemination area. This study builds and tests the model for the morning peak hour (07:00 am to 10:00 am). The assumed number of faculty/staff and students travelling during the morning peak hour to/from the campus are 1889 and 3568, respectively. These numbers are derived from the 2018 Okanagan Travel Survey (OTS) data. Several improvements have been made to simulate travel demand for the UBCO sub-area better. The description and improvements made to the existing regional demand forecasting model are described below.

\subsection{Trip Generation and Distribution}

This study updates the origin-destination (O/D) matrix based on the 2018 OTS. The spatial unit of analysis is updated as follows: for the UBCO subarea, academic buildings, on-campus housing buildings, and off-campus housing buildings in Academy Way and Quail Ridge have been considered as individual zones; in contrast, for the areas outside the campus, dissemination areas (DAs) are considered as the spatial unit of analysis. A micro-spatial resolution is necessary to simulate the scenarios for the UBCO sub-area better.

\subsection{Modal Split}

The study develops a multinomial logit model (MNL) for the mode choice component of the regional model. The model is estimated using the Biogeme software. The purpose is to use the model to predict the mode choice. The model is built using the 2018 OTS, considering the following modes as alternative options: car, public transit, walk, bike, and others. In the model specification, the utility function $\left(U_{i j}\right)$ for individual, $i(i=1,2,3, \ldots, N)$ choosing alternative travel type, $j(j=1,2,3,4,5)$ takes the following form:

$$
U_{i j}=\alpha_{j} X_{i j}+\varepsilon_{i j}
$$

where, $\alpha_{j}$ is the vector of parameters to be estimated, $X_{i j}$ is the vector of independent variables influencing individuals' $(i)$ mode choice $(j)$ and $\varepsilon_{i j}$ is the random error term. In the MNL model, the error term is assumed to be independently and identically distributed (i.i.d.) as a standard Gumbel distribution [24]. Therefore, the probability of choosing travel type, $j$ by an individual, $i$ can be expressed in the following logit form:

$$
P_{j}=\frac{e^{\alpha_{j} X_{i j}}}{\sum_{j=1}^{j} e^{\alpha_{j} X_{i j}}}
$$

\subsection{Trip Assignment}

In this modeling stage, trips are assigned into the regional road network adopting a static user equilibrium traffic assignment method which follows Wardrop's first principle [25]. This assignment method assumes that an individual chooses the routes that have minimum user travel costs and any alternate routes will result in higher costs [26].

\subsection{Calibration and Validation of Model}

The macroscopic model for the region has been calibrated and validated in a number of steps. Firstly, the mode choice model has been calibrated utilizing VISUM's demand calibration tool. A calibration parameter is introduced in the unity function of travel mode choice (presented earlier). This parameter was adjusted in an iterative process to match the predicted mode share with the observed value. After validating the mode choice at the regional level, the sub-model was further validated based on traffic flow. To accomplish this, VISUM's TFlowFuzzy algorithm has been utilized. Entropy maximization principle [27] was followed to match predicted traffic volume resulting from the traffic assignment procedure with the observed count by adjusting the previously assigned O/D matrix [28]. 
To validate the model, the GEH value for car volume on links has been calculated using the following equation:

$$
\text { GEH Value }=\sqrt{\frac{2 \times(\text { Model Count }- \text { Observed Count })^{2}}{\text { Model Count }+ \text { Observed Count }}}
$$

\subsection{Scenario Development}

Several scenarios have been developed and tested to assess how UBCO could reach their CAP 2030 target and BCs' progressive targets. During the COVID-19 pandemic, transition to remote work and online classes have demonstrated that remote working/learning arrangements are feasible strategies to mitigate GHG emissions. Therefore, this study develops and tests scenarios related to the hybrid campus in the post-pandemic new-normal future. These measures include a certain share of students, and faculties/staffs would be learning/working remotely. Under this TDM category, 30 scenarios have been developed under three categories. Under the first category, 10 scenarios are created for different shares of students participating in online classes. The second category includes 10 scenarios for different shares of faculties and staff working from home. The remaining 10 scenarios under the third category test different shares of students and faculties/staffs remotely learning/working.

This study has also assessed scenarios related to emerging technologies such as AEV. SAE International [29] has six categories depending on the level of automation: where level 0 comprises of limited features such as automatic emergency braking, providing warnings on blind spots and lane departure etc., and level 5 provides full automation feature. Level 2 cars were first deployed in 2016, which offer adaptive cruise control under human drivers' monitoring. Currently, level 2 cars are available on the market. Level 3 cars (i.e., the driver needs to take control in special circumstances, although most of the actions are performed by the vehicle) are available to consumers at a limited number and option-only Audi A8 has the level 3 feature [30]. Level 4 and level 5 cars are anticipated to hit the market in the near future. This study has assessed the impact of level 2 and level $5 \mathrm{AEVs}$ to determine short-term and long-term strategies. To account for the driving behavior of AEVs, passenger car unit (PCU) for different levels of automation has been used, which is adopted from the Susilawati and Lim [31]. The level of automation has a correlation with reaction time and road capacity [32]. In the case of level 2 AEVs, the vehicles will adopt conservative driving since the reaction time to detect a surrounding object is higher due to limited automation capability. This results in a higher vehicle-tovehicle distance and lowers the capacity of a road. Therefore, a level 2 car is assumed to have a higher PCU value (1.4). In contrast, level 5 cars will be equipped with high-tech automation capability and have a quicker reaction time. Therefore, level 5 cars will operate aggressively, maintaining lower vehicle-to-vehicle distance and have lower PCU value (0.7). The penetration rate for AEVs has been varied from $10-50 \%$ at a $10 \%$ increment. Finally, a combination of individual scenarios has been developed to assess the combined effects of hybrid AEV and hybrid campus strategies. Emissions from the car have been calculated by multiplying vehicle kilometers travelled (VKT) with emission factors provided by US Environment Protection Agency (EPA) [33]. According to US EPA, emission factors for $\mathrm{CO}_{2}, \mathrm{CH}_{4}$, and $\mathrm{NO}_{2}$ are $0.21313 \mathrm{~kg} /$ vehicle-kilometer, $0.011806 \mathrm{~g} /$ vehicle-kilometer, and $0.006835 \mathrm{~g} /$ vehicle-kilometer, respectively.

\section{Results and Discussions}

\subsection{Model Choice Model Results}

The mode choice model result is presented in Table 1 . The model yields a rho-square value of 0.690 , which is reasonably satisfactory. The results show that travel time has a negative relationship for car, walk, bike, and other modes. Interestingly, this variable has more than 10 times stronger effects on walk mode than a car. This finding implies that individuals using walk mode are significantly more sensitive to travel time than car 
users. The result also reveals that individuals are less likely to choose a car if they reside in low-income neighborhoods-i.e., DAs with a higher share of low-income (below $\$ 20,000$ ) households. The same variable shows a positive sign for transit. This indicates that the demand for transit might be higher in lower-income areas. Population density shows a positive relationship for transit, walk, and bike modes. Therefore, the higher population density will maximize the probability of a pedestrian being the travel mode, followed by bike and transit. The results further reveal that individuals are likely to choose bikes if there is a higher number of education centers in the DA. This model has been used to predict the mode choice for the region.

Table 1. Multinomial Logit Model Results for the AM-Peak Mode Choice.

\begin{tabular}{|c|c|c|}
\hline Alternative Travel Mode & Variables & Co-Efficient Value \\
\hline \multirow{3}{*}{ Car } & Constant & $3.92^{* * *}$ \\
\hline & Travel Time (mins) & $-0.00665^{* * *}$ \\
\hline & Low-income Households (below $\$ 20,000$ ) in DA & $-0.00213^{* * *}$ \\
\hline \multirow{3}{*}{ Transit } & Constant & $-0.512 * * *$ \\
\hline & Low-income Households (below $\$ 20,000$ ) in DA & $0.0123^{* * *}$ \\
\hline & Population Density in DA & $0.00012^{* * *}$ \\
\hline \multirow{3}{*}{ Walk } & Constant & $1.32^{* * *}$ \\
\hline & Travel Time (mins) & $-0.0279^{* * *}$ \\
\hline & Population Density in DA & $0.000215^{* * *}$ \\
\hline \multirow{4}{*}{ Bike } & Constant & $-0.606^{* * *}$ \\
\hline & Population Density in DA & $0.000211^{* * *}$ \\
\hline & Travel Time (mins) & $-0.00630 * * *$ \\
\hline & Number of Education Centre in DA & $0.0257^{* * *}$ \\
\hline \multirow{3}{*}{ Others } & Travel Time (mins) & $-0.000850 * * *$ \\
\hline & Low-income Households (below $\$ 20,000$ ) in DA & $-0.0143 * * *$ \\
\hline & Number of Children in DA & $0.00237^{* * *}$ \\
\hline
\end{tabular}

\subsection{Mode Choice Validation Results}

The above-described mode choice model is adjusted by introducing a calibration parameter to match the predicted mode share with the regional mode share for AM peak period. The result is presented in Figure 2, which shows that observed and predicted mode shares are close. For example, the model predicts that the share of cars and walk are $79.60 \%$ and $12.60 \%$, whereas the observed share of these two travel modes are $82.74 \%$ and $12.23 \%$, respectively. The results suggest that the model predicted modal share represents the region well.

\subsection{Traffic Volume Validation Results}

In the case of the UBCO sub-area model, traffic volume has been used as the validation parameter. The final model shows that among a total of 14 approaches in five intersections within the university, 13 links have GEH value below 5\% for cars. More than $85 \%$ of the GEH values have a value lower than $5 \%$, which indicates that the sub-model meets the GEH criterion and is reasonable for further scenario testing [34]. 


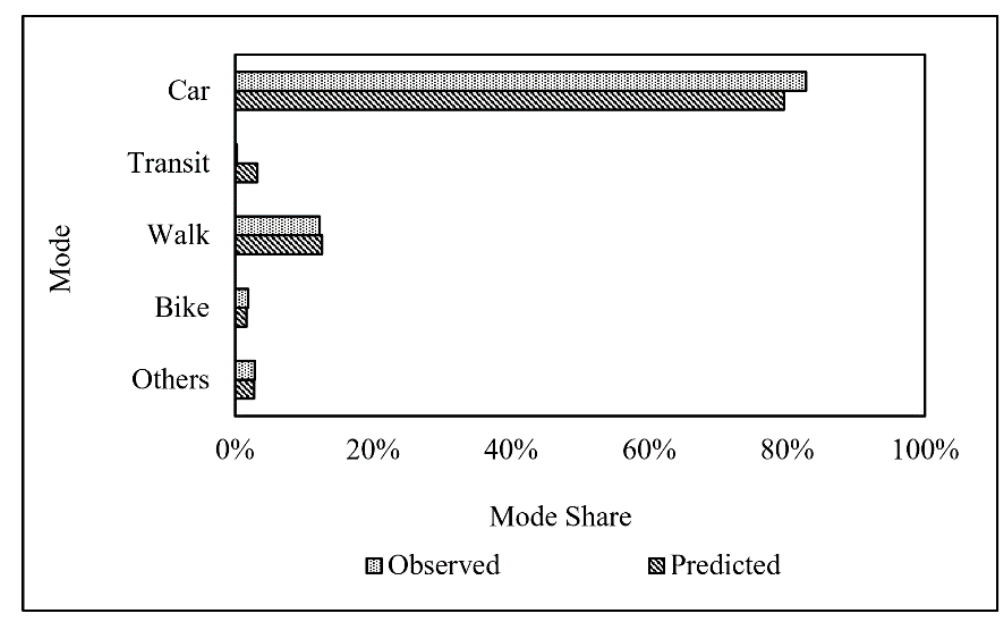

Figure 2. Validating regional travel mode share prediction using the estimated MNL model.

\subsection{Discussions on the Simulation Results to Achieve GHG Mitigation Targets}

This study estimates the amount of emissions during a typical weekday morning peak hour (7:00 am-10:00 am). Emissions from all cars travelling in the university campus during that period have been considered. The simulation results suggest that a total of $428.35 \mathrm{~kg} \mathrm{CO}_{2}, 23.72 \mathrm{~g} \mathrm{CH}_{4}$, and $13.74 \mathrm{~g} \mathrm{NO}_{2}$ have been emitted from cars in the university campus for the 2018 business-as-usual scenario. This amount of emissions has resulted from a total of 2009.8 VKT in the university campus. Utilizing this result, the study has estimated GHG emission reduction through introducing a hybrid campus and deploying autonomous vehicles considering emissions in 2018 as the baseline. In addition to that, the study has also investigated how different targets can be achieved through these actions. Different targets include targets of the government of British Columbia's CleanBC plan and UBCO's CAP 2030. In the CleanBC plan and CAP 2030, baselines were emissions in 2007 and 2013, respectively; emissions in those years have also been calculated using emissions reductions in 2018 as specified in the CleanBC plan and CAP 2030.

Table 2 reports GHG emission reduction in percentage compared to the 2018 emissions for different travel demand management strategies: different shares of students attending online class, different shares of faculties/staffs working-from-home, and combination of students and faculties/staffs remotely working/learning. Simulation results suggest that a total of $\sim 2.3 \%$ GHG can be reduced while $10 \%$ of students are attending online classes, and the GHG reduction can reach up to $\sim 23.6 \%$ if the share of students attending online classes is increased to $100 \%$. On the other hand, faculties and staffs predominantly use cars and, thus, resulting in a higher reduction in emissions.

A set of scenarios are developed by combining the above two scenarios. If $10 \%$ of students and faculties/staffs remotely learn/work, $\sim 7.2 \%$ emissions can be mitigated. If remote learning and working opportunities can be increased to $100 \%$, emissions reductions will be $\sim 76.4 \%$. In the case of the $100 \%$ remote access scenario, emissions are not fully reduced, since people travelling through UBCO to other destinations will still emit GHGs. Table 2 also suggests that the target set by UBCO's CAP 2030 (50-60\% reduction) can be achieved either by encouraging $60 \%$ or more faculties and staffs to work from home or arranging a hybrid campus for $50 \%$ or more students and faculties/staffs remotely working/learning. Furthermore, 2030's target of CleanBC plan ( $40 \%$ reduction) is also achievable adopting similar scenarios. On the other hand, 2040's target can be met by arranging a virtual work environment for $90 \%$ or more faculties/staffs or introducing virtual work and classes for $70 \%$ or more of the students and faculties/staffs. Lastly, the target for 2050 can only be achieved by $100 \%$ of students, faculties and staff attending a virtual campus. Interestingly, only making the campus virtual for students does not help achieve any target. In the base scenario, the share of students driving a car is $12.9 \%$ while 
the share of faculty /staff is $76.7 \%$. Since a small portion of total students use a car, scenarios based on students attending virtual classes do not meet any emission reduction target.

Table 2. Percentage Reduction in GHG Emission and Achievable Targets for the Hybrid Campus Scenarios.

\begin{tabular}{|c|c|c|c|c|c|c|c|}
\hline $\begin{array}{l}\% \text { of Students } \\
\text { Attending } \\
\text { Online Class }\end{array}$ & $\begin{array}{c}\% \text { GHG } \\
\text { Emission } \\
\text { Reduction }\end{array}$ & $\begin{array}{l}\% \text { of Facul- } \\
\text { ties/Staffs } \\
\text { Working- } \\
\text { From-Home }\end{array}$ & $\begin{array}{c}\text { \% GHG } \\
\text { Emission } \\
\text { Reduction }\end{array}$ & $\begin{array}{c}\text { Achievable } \\
\text { Targets }\end{array}$ & $\begin{array}{l}\% \text { of Students and } \\
\text { Faculties/Staffs } \\
\text { Learning/Working } \\
\text { Remotely }\end{array}$ & $\begin{array}{c}\% \text { GHG } \\
\text { Emission } \\
\text { Reduction }\end{array}$ & $\begin{array}{c}\text { Achievable } \\
\text { Targets }\end{array}$ \\
\hline (a) & (a) & (b) & (b) & (b) & (c) & (c) & (c) \\
\hline $10 \%$ & $2.3 \%$ & $10 \%$ & $4.4 \%$ & & $10 \%$ & $7.2 \%$ & \\
\hline $20 \%$ & $4.5 \%$ & $20 \%$ & $13.8 \%$ & & $20 \%$ & $19.4 \%$ & \\
\hline $30 \%$ & $7.6 \%$ & $30 \%$ & $20.4 \%$ & & $30 \%$ & $24.7 \%$ & \\
\hline $40 \%$ & $8.7 \%$ & $40 \%$ & $25.6 \%$ & & $40 \%$ & $35.3 \%$ & \\
\hline $50 \%$ & $11.1 \%$ & $50 \%$ & $33.3 \%$ & & $50 \%$ & $43.3 \%$ & \\
\hline $60 \%$ & $12.9 \%$ & $60 \%$ & $38.3 \%$ & & $60 \%$ & $53.7 \%$ & \\
\hline $70 \%$ & $17.3 \%$ & $70 \%$ & $44.3 \%$ & & $70 \%$ & $58.8 \%$ & \\
\hline $80 \%$ & $19.3 \%$ & $80 \%$ & $52.6 \%$ & & $80 \%$ & $65.2 \%$ & \\
\hline $90 \%$ & $22.1 \%$ & $90 \%$ & $61.1 \%$ & & $90 \%$ & $71.8 \%$ & \\
\hline $100 \%$ & $23.6 \%$ & $100 \%$ & $69.8 \%$ & & $100 \%$ & $76.4 \%$ & \\
\hline
\end{tabular}

(a) Only students attending online classes. (b) Only faculties/staffs working-from-home. (c) Both students and faculty/staff remotely working/learning. UBCO's target (50-60\% reduction by 2030; baseline: 2013). Short-term target of CleanBC Plan (40\% reduction by 2030; baseline: 2007). Intermediate target of CleanBC Plan (60\% reduction by 2040; baseline: 2007). Long-term target of CleanBC Plan (80\% reduction by 2050; baseline: 2007).

The next set is to introduce different penetration rates of AEVs for different remote learning/working scenarios. The scenario development also considers alternative PCU values-i.e., represents the autonomation level. The results are presented in Table 3. If the penetration rate of level $2 \mathrm{AEVs}$ is $10 \%$, and all students and faculties/staffs are attending school in-person, then the amount of reduction in GHG emission is $\sim 3.0 \%$. GHG could be reduced by up to $\sim 44.6 \%$ for a $50 \%$ penetration rate of $\mathrm{AEV}$ and a fully in-person campus. For the same penetration rates of level 2 AEVs, if $10 \%$ of students and faculties/staffs remotely learning/working, a higher GHG reduction can be achieved. A similar trend has been observed if level $5 \mathrm{AEVs}$ are introduced into the network. However, compared to the level 2 AEVs, a higher GHG reduction (i.e., $~ 7.5 \%$ ) can be achieved for a $10 \%$ penetration rate of level 5 AEVs and a fully in-person campus. For the level 5 environment, AEVs may drive aggressively maintaining a lower car-to-car distance, which indicates an increase in the road capacity $[31,32]$. This further refers that more cars would be able to adopt the shortest route over a longer route with the improvement in automation. As a result, the total travel time and distance are reduced, consequently reducing GHG emissions. In contrast, fewer emissions will be reduced for level 5 than level 2 AEVs for higher penetration rates. For example, at a $20 \%$ penetration rate and fully in-person campus, the level 5 AEV scenario generates an additional 4.4\% GHG compared to level 2. This result indicates that at a higher penetration rate, a higher number of level 5 AEVs might take the shortest route by driving aggressively. Hence, although the road capacity is increased with higher penetration rates of AEV level 5, most of this additional capacity along the shortest route is likely to be taken by the level $5 \mathrm{AEV}$ - pushing more conventional vehicles to longer routes. A similar observation was made by Tomás et al [35]. In this case, less reduction in GHG can be achieved for a higher penetration rate of level $5 \mathrm{AEVs} \mathrm{compared}$ to level 2. In contrast, if the overall volume of cars is reduced by allowing students and faculties/staffs to attend a virtual campus, fewer conventional cars will take longer routes. Thus, a higher amount of GHG emissions can be reduced. For example, level 5 cars would reduce an additional $2.4 \%$ of GHG emissions than level $2 \mathrm{AEVs}$ if $10 \%$ of students, faculties and staffs attend a virtual campus. Based on these results, targets outlined in CAP 2030 can be achieved by adopting at least a $40 \%$ penetration rate of level 2 or level 5 AEVs 
with/without introducing a virtual campus. Similar scenarios can be adopted to achieve the 2030s' target of the CleanBC plan. On the other hand, CleanBC's target for 2040 can be achieved with a higher penetration of AEVs (50\% or above) with a lower percentage $(10 \%$ or above) of students and faculties/staffs attending a virtual campus. However, CleanBC's target for 2050 cannot be achieved with AEV's penetration rate up to $50 \%$ along with remote working/learning by a lower percentage $(10 \%)$ of students and faculties/staffs.

Table 3. Percentage Reduction in GHG Emission and Achievable Targets for the AEV Scenarios.

\begin{tabular}{|c|c|c|c|c|c|c|c|c|}
\hline \multirow{3}{*}{$\begin{array}{c}\text { Penetration } \\
\text { Rates }\end{array}$} & \multicolumn{4}{|c|}{ AEV Level $2($ PCU = 1.4) } & \multicolumn{4}{|c|}{ AEV Level $5(\mathrm{PCU}=0.7)$} \\
\hline & \multicolumn{2}{|c|}{ (a) } & \multicolumn{2}{|c|}{ (b) } & \multicolumn{2}{|c|}{ (a) } & \multicolumn{2}{|c|}{ (b) } \\
\hline & $\begin{array}{c}\% \text { GHG } \\
\text { Reduction }\end{array}$ & $\begin{array}{l}\text { Achievable } \\
\text { Targets }\end{array}$ & $\begin{array}{c}\% \text { GHG } \\
\text { Reduction }\end{array}$ & $\begin{array}{l}\text { Achievable } \\
\text { Targets }\end{array}$ & $\begin{array}{c}\% \text { GHG } \\
\text { Reduction }\end{array}$ & $\begin{array}{l}\text { Achievable } \\
\text { Targets }\end{array}$ & $\begin{array}{c}\% \text { GHG } \\
\text { Reduction }\end{array}$ & $\begin{array}{c}\text { Achievable } \\
\text { Targets }\end{array}$ \\
\hline $10 \%$ & $3.0 \%$ & & $13.5 \%$ & & $7.5 \%$ & & $14.9 \%$ & \\
\hline $20 \%$ & $15.8 \%$ & & $21.4 \%$ & & $14.4 \%$ & & $23.8 \%$ & \\
\hline $30 \%$ & $27.6 \%$ & & $31.4 \%$ & & $23.9 \%$ & & $34.1 \%$ & \\
\hline $40 \%$ & $35.7 \%$ & & $39.8 \%$ & & $34.6 \%$ & & $41.6 \%$ & \\
\hline $50 \%$ & $44.6 \%$ & & $48.4 \%$ & & $44.4 \%$ & & $48.3 \%$ & \\
\hline
\end{tabular}

(a) In Person Class. (b) 10\% students participating in online class, $10 \%$ faculties/staffs working-from-home. duction by 2030; baseline: 2013). \$ Short-term target of CleanBC Plan (40\% reduction by 2030; baseline: 2007). Intermediate target of CleanBC Plan (60\% reduction by 2040; baseline: 2007).

\section{Conclusions}

This paper presents the simulation results for adopting alternative aggressive travel demand management strategies and emerging technologies and demonstrates how the University of British Columbia's Okanagan (UBCO) campus can achieve their climate action goals. UBCO is working together with the provincial government to achieve progressive goals declared in the CleanBC plan. Travel demand management strategies refer to alternative virtual campus scenarios, including different shares of students attending online classes, different shares of faculties/staffs working-from-home, and a hybrid campus, which refers to a different combination of students and faculties/staffs remotely working/learning. In the case of the emerging technologies scenarios, alternative penetration rates for different levels (i.e., level 2 and 5) autonomous electric vehicles (AEVs) have been developed. The AEV scenarios are developed for in-person campus and hybrid campus cases. A total of 50 scenarios have been developed. To test these scenarios, a sub-area transport simulation model for UBCO is developed. This sub-area model is extracted from the existing regional travel demand forecasting model. This study updates the regional model, such as estimates a mode choice model and validates it. Then the UBCO sub-area model is further calibrated and validated.

The simulation results suggest that a hybrid campus can significantly reduce GHG emissions. The results revealed that UBCO's target to mitigate extended impacts emission (i.e., $50-60 \%$ reduction by 2030 compared to the 2013 level) could be achieved by allowing at least $50 \%$ of students and faculties / staffs to attend school remotely. In the case of the targets set in the CleanBC plan by the Government of British Columbia, short-term targets to reduce $40 \%$ GHG reduction by 2030 compared to the 2007 level can be achieved by adopting the same strategy. If the hybrid campus percentage is incremented to $70 \%, 2040$ 's target to reduce $50 \%$ emission can be met. To achieve the long-term target (i.e., $60 \%$ reductions by 2050 compared to the 2013 level), the hybrid campus needs to be fully virtual. In the case of the AEV scenario, a 40\% AEV penetration rate or above will help achieve UBCO's extended impacts emission reduction target and $\mathrm{BC}^{\prime}$ 's short-term target. On the other hand, 2040's target of BC is achievable under a 50\% penetration rate of $\mathrm{AEV}$ and a $10 \%$ hybrid virtual campus. The AEV scenarios provided some interesting findings. The results suggested that higher penetration of AEV results in a higher amount of GHG reduction. The amount of GHG emission reduction can increase if AEVs are deployed in conjunction 
with hybrid virtual campus-e.g., $10 \%$ of students and faculties/staffs attend virtual school. Interestingly, at a lower penetration rate (e.g., 10\%), level $5 \mathrm{AEVs}$ will reduce more GHG emissions compared to level 2 AEVs. However, less GHG emissions will be reduced for higher penetration rates of level $5 \mathrm{AEVs}$ than level 2 for the fully in-person campus scenario. However, if the overall car traffic is reduced by adopting a hybrid virtual campus coupled with higher penetration rates of level $5 \mathrm{AEVs}$, the GHG emissions reduction in such cases improves. There are few limitations in this study. For example, the morning peak-hour was considered as a case study. Future research should investigate 24-hour GHG emissions. Furthermore, this study only considered tail-pipe emissions for passenger cars and AEVs. Therefore, electricity generation for AEV charging, batteries, and manufacturing, and subsequent emissions have not been considered in this study, which can be identified as another limitation. In this macroscopic simulation modeling exercise, explicit modeling of AEV driving behavior, for example, interactions between autonomous and human driven vehicles in a mixed traffic roadway was not considered. Future research should develop a microscopic simulation model to assess alternative driving behavior scenarios such as minimum car-to-car distance for level 2 and level 5 AEVs. Lastly, this study only focuses on analyzing emissions reduction from the transportation sector through virtual campus strategies such as work-from-home and remote learning. Although COVID-19 imposed telecommuting and remote learning strategies might have reduced emissions from the transportation sector significantly, there might be a rebound effect of it [36]. For example, instead of traveling to work, individuals are working from home--leading to that they are spending more time at home, which further indicates an increased energy consumption and emissions from the residential sector due to longer duration at home. Although the scope of this study does not include residential energy and emissions analysis, another study from our research group has explored this question [37]. One of the immediate future studies should focus to take an integrated approach combining these two studies to offer insights on the total reduction in emissions (i.e., analyzing transportation and residential sector emissions) through the virtual campus option. Another dimension for the future research should be to explore the reduction in emissions from the university buildings for the virtual campus strategy. The evidence generated through this study can be used for developing UBCO's transportation master plan, which is currently under development. Over the growing concern of GHG emission increase worldwide, this study presents how a major employer like UBCO can become a role model by adopting aggressive strategies to cut their carbon footprint and achieve their climate action target, consequently helping the government to achieve theirs.

Author Contributions: The authors confirm contribution to the paper as follows: study conception and design: M.R.F. and B.S., data collection: M.R.F. and B.S., analysis and interpretation of results: B.S. and M.R.F., draft manuscript preparation: B.S. and M.R.F. All authors have read and agreed to the published version of the manuscript.

Funding: The study was financially supported by the Rogers Communications and Mitacs Accelerate (Grant number: GR019822). The study also received support from NSERC through discovery grant (Grant number: GR013952).

Institutional Review Board Statement: Not applicable.

Informed Consent Statement: Not applicable.

Data Availability Statement: Data are not publicly available.

Acknowledgments: The authors would like to thank the City of Kelowna, The University of British Columbia and Bluecity for providing the data. Special thanks to Mike Kennedy, Anas Chaaban and Mohammad Pourmeydani for their insights and help during data collection, model development and scenario development.

Conflicts of Interest: The authors declare no conflict of interest. 


\section{References}

1. Fast Facts: U.S. Transportation Sector Greenhouse Gas Emissions 1990-2019. Available online: https://www.epa.gov/ greenvehicles / fast-facts-transportation-greenhouse-gas-emissions (accessed on 19 October 2021).

2. Perveen, S.; Yigitcanlar, T.; Kamruzzaman, M.; Agdas, D. How Can Transport Impacts of Urban Growth Be Modelled? An Approach to Consider Spatial and Temporal Scales. Sustain. Cities Soc. 2020, 55, 102031. [CrossRef]

3. Healthy Environment and a Healthy Economy: Canada's Strengthened Climate Plan to Create Jobs and Support People, Communities and the Planet. Available online: https://www.canada.ca/content/dam/eccc/documents/pdf/climate-change/ climate-plan/healthy_environment_healthy_economy_plan.pdf (accessed on 19 October 2021).

4. Government of British Columbia. CleanBC. Available online: https://www2.gov.bc.ca/gov/content/environment/climatechange/planning-and-action (accessed on 19 October 2021).

5. Pérez-Neira, D.; Rodríguez-Fernández, M.P.; Hidalgo-González, C. The Greenhouse Gas Mitigation Potential of University Commuting: A Case Study of the University of León (Spain). J. Transp. Geogr. 2020, 82, 102550. [CrossRef]

6. Climate Action Plan 2030: Emerging Directions and Draft Targets for UBC Vancouver and Okanagan Campuses. Available online: https://bog3.sites.olt.ubc.ca/files/2021/01/6_2021.02_Climate-Action-Plan-2030.pdf (accessed on 19 October 2021).

7. UBC Okanagan Transportation Plan—Phase 1: Public Consultation Summary Report. Available online: https://campusplanning ok.ubc.ca/projects/ubc-okanagan-transportation-plan/ (accessed on 19 October 2021).

8. Valtonen, T.; Leppänen, U.; Hyypiä, M.; Kokko, A.; Manninen, J.; Vartiainen, H.; Sointu, E.; Hirsto, L. Learning Environments Preferred by University Students: A Shift toward Informal and Flexible Learning Environments. Learn. Environ. Res. 2020, 24, 371-388. [CrossRef]

9. Pata, U.K. How Is COVID-19 Affecting Environmental Pollution in US Cities? Evidence from Asymmetric Fourier Causality Test. Air Qual. Atmos. Health 2020, 13, 1149-1155. [CrossRef] [PubMed]

10. Eregowda, T.; Chatterjee, P.; Pawar, D.S. Impact of Lockdown Associated with COVID19 on Air Quality and Emissions from Transportation Sector: Case Study in Selected Indian Metropolitan Cities. Environ. Syst. Decis. 2021, 41, 401-412. [CrossRef] [PubMed]

11. Han, P.; Cai, Q.; Oda, T.; Zeng, N.; Shan, Y.; Lin, X.; Liu, D. Assessing the Recent Impact of COVID-19 on Carbon Emissions from China Using Domestic Economic Data. Sci. Total Environ. 2021, 750, 141688. [CrossRef] [PubMed]

12. Zhang, R.; Zhang, J. Long-Term Pathways to Deep Decarbonization of the Transport Sector in the Post-COVID World. Transp. Policy 2021, 110, 28-36. [CrossRef] [PubMed]

13. Fernandes, P.; Bandeira, J.M.; Coelho, M.C.; Fernandes, P.; Bandeira, J.M.; Coelho, M.C. A Macroscopic Approach for Assessing the Environmental Performance of Shared, Automated, Electric Mobility in an Intercity Corridor. J. Intell. Transp. Syst. 2021, 1-17. [CrossRef]

14. Patella, S.M.; Scrucca, F.; Asdrubali, F.; Carrese, S. Carbon Footprint of Autonomous Vehicles at the Urban Mobility System Level: A Traffic Simulation-Based Approach. Transp. Transp. Res. Part D Transp. Environ. 2019, 74, 189-200. [CrossRef]

15. Pourrahmani, E.; Jaller, M.; Maizlish, N.; Rodier, C. Health Impact Assessment of Connected and Autonomous Vehicles in San Francisco, Bay Area. Transp. Res. Rec. 2020, 2674, 898-916. [CrossRef]

16. Le Hong, Z.; Zimmerman, N. Air Quality and Greenhouse Gas Implications of Autonomous Vehicles in Vancouver, Canada. Transp. Res. Part D Transp. Environ. 2021,90, 102676. [CrossRef]

17. Logan, K.G.; Nelson, J.D.; Osbeck, C.; Chapman, J.D.; Hastings, A. The Application of Travel Demand Management Initiatives within a University Setting. Case Stud. Transp. Policy 2020, 8, 1426-1439. [CrossRef]

18. Filimonau, V.; Archer, D.; Bellamy, L.; Smith, N.; Wintrip, R. The Carbon Footprint of a UK University during the COVID-19 Lockdown. Sci. Total Environ. 2021, 756, 143964. [CrossRef] [PubMed]

19. UBC Okanagan 2013 Annual Report on Enrolment: Okanagan Campus. Available online: https://senate.ubc.ca/files/ downloads / ok_enrolment_report_2013_2014.pdf (accessed on 19 October 2021).

20. The University of British Columbia 2018/19 Annual Enrolment Report. Available online: https://academic.ubc.ca/academiccommunity/news-announcements /news/read-201819-annual-report-enrolment (accessed on 19 October 2021).

21. UBC Okanagan Outlook 2040. Available online: https://okmain.cms.ok.ubc.ca/wp-content/uploads/sites/26/2019/02/UBCOOutlook-2040.pdf (accessed on 19 October 2021).

22. Chalaki, B.; Beaver, L.E.; Remer, B.; Jang, K.; Vinitsky, E.; Bayen, A.M.; Malikopoulos, A.A. Zero-Shot Autonomous Vehicle Policy Transfer: From Simulation to Real-World via Adversarial Learning. In Proceedings of the 2020 IEEE 16th International Conference on Control \& Automation (ICCA), Singapore, 9-11 October 2020; pp. 35-40. [CrossRef]

23. PTV AG. PTV Visum 2021 Manual; PTV AG: Karlsruhe, Germany, 2021.

24. Lee, D.; Derrible, S.; Pereira, F.C. Comparison of Four Types of Artificial Neural Network and a Multinomial Logit Model for Travel Mode Choice Modeling. Transp. Res. Rec. 2018, 2672, 101-112. [CrossRef]

25. Wardrop, J.G. Some theoretical aspects of road traffic research. Proc. Inst. Civ. Eng. 1952, 1, 325-362. [CrossRef]

26. Schneck, A.; Nökel, K. Accelerating Traffic Assignment with Customizable Contraction Hierarchies. Transp. Res. Rec. 2020, 2674, 188-196. [CrossRef]

27. Van Zuylen, H.J.; Willumsen, L.G. The Most Likely Trip Matrix Estimated from Traffic Counts. Transp. Res. Part B Methodol. 1980, 14, 281-293. [CrossRef] 
28. Li, X.; Lopes, D.; Mok, K.M.; Miranda, A.I.; Yuen, K.V.; Hoi, K.I. Development of a Road Traffic Emission Inventory with High Spatial-Temporal Resolution in the World's Most Densely Populated Region-Macau. Environ. Monit. Assess. 2019, 191, 239. [CrossRef]

29. SAE International Taxonomy and Definitions for Terms Related to Driving Automation Systems for On-Road Motor Vehicles. Available online: https://www.sae.org/standards/content/j3016_202104/(accessed on 19 October 2021).

30. Alsalman, A.; Assi, L.N.; Ghotbi, S.; Ghahari, S.; Shubbar, A. Users, Planners, and Governments Perspectives: A Public Survey on Autonomous Vehicles Future Advancements. J. Transp. Eng. 2021, 3, 100044. [CrossRef]

31. Lim, T.S. A Study of the Scheduling Effect on Shared Autonomous Vehicles Adoption. Transp. Res. Interdiscip. Perspect. 2021, 10, 100394. [CrossRef]

32. Madadi, B.; van Nes, R.; Snelder, M.; van Arem, B. Assessing the Travel Impacts of Subnetworks for Automated Driving: An Exploratory Study. Case Stud. Transp. Policy 2019, 7, 48-56. [CrossRef]

33. Environmental Projection Agency Emission Factor for Greenhouse Gas Inventories. Available online: https: / www.epa.gov / sites/default/files/2018-03/documents/emission-factors_mar_2018_0.pdf (accessed on 19 October 2021).

34. El Hamra, W.; Attallah, Y. The Role of Vehicles' Identification Techniques in Transportation Planning-Modeling Concept. Alex. Eng. J. 2011, 50, 391-398. [CrossRef]

35. Tomás, R.F.; Fernandes, P.; MacEdo, E.; Bandeira, J.M.; Coelho, M.C. Assessing the Emission Impacts of Autonomous Vehicles on Metropolitan Freeways. Transp. Res. Procedia 2020, 47, 617-624. [CrossRef]

36. Guerin, T.F. Policies to minimise environmental and rebound effects from telework: A study for Australia. Environ. Innov. Soc. Transit. 2021, 39, 18-33. [CrossRef]

37. Khalil, M.A.; Fatmi, M. Developing an Agent-based Model to Simulate Residential Energy Consumptions: Assessing the Impacts of the COVID-19 Pandemic. Transp. Res. Board 2021, 1-23. 